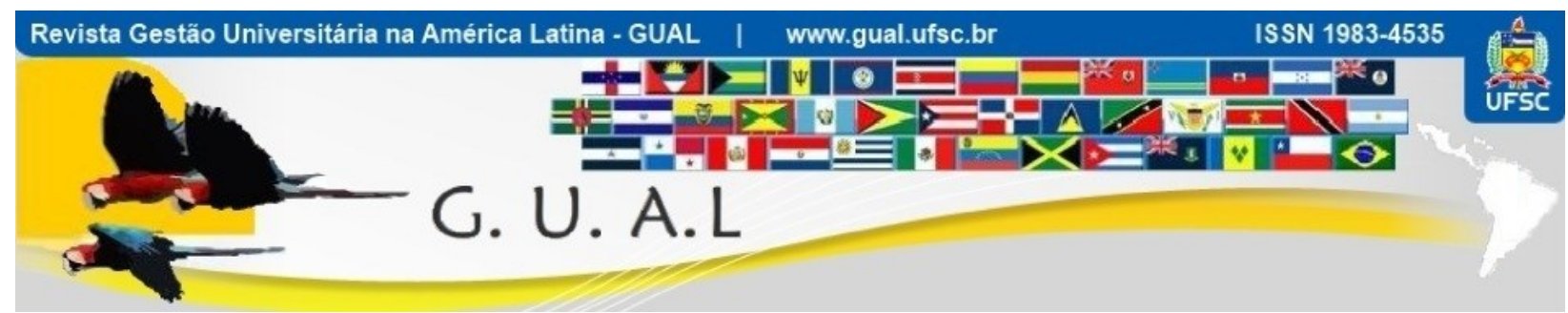

DOI: http://dx.doi.org/10.5007/1983-4535.2019v12n2p230

\title{
PRÁTICAS SUSTENTÁVEIS: ESTUDO DE CASO EM UMA INSTITUIÇÃO DE ENSINO SUPERIOR
}

\section{SUSTAINABLE PRACTICES: A CASE STUDY IN HIGHER EDUCATION INSTITUTION}

\author{
Carol Soares Bezerra de Sá Peixoto, Especialista \\ https://orcid.org/0000-0003-3305-7508 \\ carolsb_peixoto@hotmail.com \\ Universidade Federal Rural de Pernambuco | Unidade Acadêmica de Garanhuns \\ Garanhuns | Pernambuco | Brasil
}

\author{
Rodolfo Araújo de Moraes Filho, Doutor \\ https://orcid.org/0000-0003-4410-2941 \\ rodolfoamfilho@yahoo.com.br \\ Universidade Federal Rural de Pernambuco | Departamento de Administração \\ Recife | Pernambuco | Brasil \\ Ionete Cavalcanti de Moraes, Doutora \\ https://orcid.org/0000-0003-0621-618X \\ ionetemoraes@gmail.com \\ Universidade Federal Rural de Pernambuco | Departamento de Administração \\ Recife | Pernambuco | Brasil
}

Larissa Gomes Holanda de Sá Vieira, Especialista https://orcid.org/0000-0002-7086-929 larissagomes@gmail.com Universidade Federal Rural de Pernambuco | Mestrado Profissional em Administração Pública em Rede Nacional Recife | Pernambuco | Brasil

Marlon Esdras Jessé de Souza, Licenciado https://orcid.org/0000-0002-4637-189X marlonesdras@hotmail.com Universidade Federal Rural de Pernambuco | Unidade Acadêmica de Garanhuns Garanhuns | Pernambuco | Brasil

Recebido em 17/julho/2018

Aprovado em 19/fevereiro/2019

Publicado em 02/maio/2019

Sistema de Avaliação: Double Blind Review

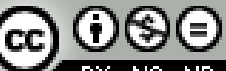

Esta obra está sob uma Licença Creative Commons Atribuição-Uso. 


\title{
RESUMO
}

As Instituições Públicas de Ensino Superior podem ser entendidas como grandes consumidoras de bens e serviços, no caso do Brasil. Para diminuir os impactos negativos desse consumo, essas entidades possuem função primordial na difusão e implantação de ideias sustentáveis. Assim, esse estudo investigou as práticas sustentáveis adotadas pelos técnicos administrativos da Universidade Federal Rural de Pernambuco - Unidade Acadêmica de Garanhuns (UFRPE/UAG), observando os eixos da Agenda Ambiental da Administração Pública (A3P), bem como o grau de conhecimento desses servidores sobre temáticas de sustentabilidade na Administração Pública. Utilizou-se como metodologia de abordagem o estudo de caso, sendo a pesquisa classificada como descritiva, de natureza qualitativa. Para o levantamento de dados, aplicou-se um questionário junto aos técnicos administrativos da Unidade e uma entrevista semiestruturada com o Diretor Administrativo. Os resultados demonstraram que na UFRPE/UAG existem várias iniciativas de ações sustentáveis, porém, não se percebeu nenhuma política institucional que vise o desenvolvimento sustentável da organização. Observou-se ainda que, os técnicos possuem conhecimento limitado sobre instrumentos de implantação de práticas sustentáveis, podendo acarretar dificuldades futuras para o estabelecimento dessas ações na Unidade estudada. A partir desses resultados, concluise que as medidas de sustentabilidade preconizadas pela A3P ainda não se encontram consolidadas na instituição.

Palavras-chave: Sustentabilidade. Administração Pública. A3P.

\begin{abstract}
The higher education public institutions can be considered the largest consumer of goods and services, in the case of Brazil. In order to reduce the negative impacts of this consumption, these Institutions have a primary role in the diffusion and implantation of sustainable ideas. Thus, this paper investigated the sustainable practices adopted by the UFRPE / UAG technical-administrative staff, observing the Schedule Environmental Public Administration (A3P) axes and the public servants knowledge degree about Public Administration sustainability issues. In this research was used the case study as approach method with descriptive character and qualitative approach. In data collection, a questionnaire was applied to the technical-administrative and a semi-structured interview was conducted with the administrative director. The results showed that in UFRPE / UAG there are several specific and individual initiatives of sustainable actions, however, no institutional policy that aims the organization sustainable development has been perceived. It was also observed that the technical-administrative have limited knowledge about the instruments to implement sustainable practices in public administration which may cause difficulties in establishing these actions. From these results, it can be concluded that the sustainability measures recommended by the $\mathrm{A} 3 \mathrm{P}$ have not yet been consolidated in the institution.
\end{abstract}

Keywords: Sustainability. Public administration. A3P. 


\section{INTRODUÇÃO}

O consumo desenfreado de recursos naturais, ocasionado pelos novos modelos de produção, geram transformações significativas e preocupantes no ambiente natural. Essas transformações podem ser atribuídas ao desperdício generalizado e a problemas ambientais globais, como o aumento da temperatura na terra, a destruição da camada de ozônio e outros, consequências diretas da industrialização, do capitalismo e do modernismo (MACIEL; FREITAS, 2014; RUFINO; ANDRADE, 2014). A partir disso, a sociedade começa a se preocupar em promover o desenvolvimento sustentável, pautado no consumo consciente, na responsabilidade social e na eficiência econômica, com o menor dano possível ao meio ambiente.

Nesse mesmo sentido, as discussões sobre a temática do desenvolvimento sustentável passam a despertar também o interesse de órgãos governamentais e de empresas de âmbito privado. Para Pedroso (2007), essas organizações vêm incorporando os conceitos de sustentabilidade às suas práticas de gestão por ser uma necessidade demandada por uma sociedade mais ambientalmente consciente.

Segundo Carvalho e Sousa (2013), a administração pública é responsável por movimentar de $10 \%$ a $15 \%$ do Produto Interno Bruto (PIB) brasileiro, sendo considerada a maior consumidora de bens e serviços do mercado. Esse fato reforça a necessidade das instituições públicas brasileiras implantarem um sistema de gestão ambiental que promova ações sustentáveis com a pretensão de diminuir a geração de resíduos, os impactos ambientais e os desperdícios, advindos de suas atividades diárias (COGO; OLIVEIRA; TESSER, 2012; PEGORIN; SANTOS; MARTINS, 2014). Com isso, a Administração Pública brasileira tem desenvolvido diversas políticas que visam à promoção da sustentabilidade em suas práticas de gestão. Dentre elas, pode-se ressaltar a Agenda Ambiental na Administração Pública (A3P), desenvolvida a partir das diretrizes da Agenda 21 e do Plano de Gestão de Logística Sustentável (PLS).

No que diz respeito aos órgãos do setor público, as Instituições de Ensino Superior (IES) possuem papel essencial na difusão do pensamento sustentável, pois, além de serem organismos formadores de opinião e pensamento, devem servir de exemplo à sociedade, e implantar os conceitos do desenvolvimento sustentável nas rotinas de trabalho de seu ambiente laboral (GAZZONNI et al., 2018). O pensamento sustentável, em sua essência, pode depender apenas de atitudes simples, como o reaproveitamento de material, economia de água 
e energia elétrica, que podem ser desenvolvidas por cada servidor em seu local de trabalho (MACULAN et al., 2016). Para Pereira (2013), a implantação de ideias sustentáveis em IES só ocorre devido à vontade e motivação dos alunos, professores e técnicos administrativos, em concretizar essas ideias.

Nesse contexto, o objetivo do estudo é investigar as práticas sustentáveis adotadas pelos técnicos administrativos na Universidade Federal Rural de Pernambuco - Unidade Acadêmica de Garanhuns, observando os eixos propostos pela A3P. Buscou-se analisar ainda, qual o grau de conhecimento desses técnicos a respeito de algumas temáticas de sustentabilidade da Administração Pública.

Esse estudo se justifica por contribuir com as pesquisas que envolvem a temática do desenvolvimento sustentável nas instituições públicas, especialmente aquelas voltadas para a educação de nível superior. Além disso, busca-se colaborar na construção de práticas de gestão voltadas para a redução do desperdício, com administração adequada dos resíduos gerados e utilização apropriada dos recursos naturais, humanos e econômicos disponíveis.

No que tange à organização deste artigo, além desta introdução, há ainda mais cinco seções: Fundamentação teórica - Apresenta o embasamento teórico da pesquisa; Metodologia - Descreve os procedimentos metodológicos utilizados; Análise dos resultados - Expõe os resultados encontrados com a realização da pesquisa; e Considerações finais - Apresenta as conclusões e sugestões de estudos futuros.

\section{FUNDAMENTAÇÃO TEÓRICA}

\subsection{DESENVOLVIMENTO SUSTENTÁVEL NA ADMINISTRAÇÃO PÚBLICA}

O conceito de desenvolvimento sustentável foi amplamente disseminado a partir de 1987, quando o relatório "Nosso Futuro Comum", redigido pela Comissão Mundial sobre Meio Ambiente e Desenvolvimento das Nações Unidas, definiu-o como "aquele que atende às necessidades do presente sem comprometer a possibilidade das gerações futuras atenderem às suas próprias necessidades" (BRUNDTLAND et. al., 1991, p. 46).

Nesse sentido, é importante salientar que, como bem destacado por Luiz, Pfitscher e Rosa (2015, p. 9-10):

[...] todas as circunstâncias que ocasionam a fragilidade e a destruição do meio ambiente instigaram reflexões sobre o desenvolvimento e os problemas ocasionados por padrões de vida incompatíveis com o processo de regeneração do meio ambiente, levando ao conceito de desenvolvimento sustentável, um tipo de desenvolvimento que garante a qualidade de vida para as atuais e futuras gerações, sem destruir a base de sustentação: o meio ambiente. 
Para Barbieri et al. (2010) e Lima, Slomski e Rocha (2013), a sustentabilidade possui 3 dimensões: (1) dimensão social - leva em consideração os impactos sociais nas comunidades humanas (poder e equidade, mobilidade social, gestão social e identidade cultural); (2) dimensão ambiental - considera os impactos ambientais pelo uso de recursos naturais e pelas emissões de poluentes; (3) dimensão econômica - preocupação com a eficiência econômica, inovação e valor para os acionistas. Essas dimensões são conhecidas como Triple Bottom Line (TBL), expressão criada em 1994, pelo inglês John Elkington, que definiu esses pilares para nortear a gestão das empresas em relação à sustentabilidade (RODRIGUES, 2015). Conforme Bernardes et al. (2016), o TBL é a base do desenvolvimento sustentável, e este só ocorre quando da prática de todas as dimensões, ao mesmo tempo e em sua totalidade.

No que tange à adoção de práticas sustentáveis por parte dos órgãos públicos brasileiros, podemos citar a Carta Magna de 1988, que em seu artigo 225, já alertava sobre a questão ambiental e sobre a responsabilidade do Poder Público em defender e preservar o meio ambiente para as presentes e futuras gerações (BRASIL, 1988). De acordo com Soares et al. (2017), essa normativa demonstra que a questão ambiental já era alvo de preocupação e inquietação por parte dos administradores públicos brasileiros naquela época.

Em 1992, a ONU realizou no Rio de Janeiro, a Conferência das Nações Unidas sobre o Meio Ambiente e o Desenvolvimento (CNUMAD), também conhecida como Rio 92, um dos eventos mais importantes para a temática da sustentabilidade, que contou com a presença de chefes de estado de várias nações. Nessa Conferência, o conceito de desenvolvimento sustentável foi consagrado e adquiriu plena cidadania, aparecendo em quase todos os documentos produzidos nesta reunião (BOFF, 2017).

Um desses documentos foi a "Agenda 21: Programa de ação global”, a qual possui 40 capítulos, que projetam programas de ação para a participação de todos os segmentos da sociedade, na formulação de políticas e práticas que conciliam métodos de proteção ambiental, justiça social e eficiência econômica (MELLO; OJIMA, 2004; VELTER et al., 2010; FERREIRA et al., 2015). O capítulo 4 (item 4.23) dessa Agenda estabelece:

Os próprios Governos também desempenham um papel no consumo, especialmente nos países onde o setor público ocupa uma posição preponderante na economia, podendo exercer considerável influência tanto sobre as decisões empresariais como sobre as opiniões do público. Consequentemente, esses Governos devem examinar as políticas de aquisição de suas agências e departamentos de modo a aperfeiçoar, sempre que possível, o aspecto ecológico de suas políticas de aquisição (ONU, 1992). 
Dessa forma, pode-se perceber que esse instrumento enfatizou o dever do Estado em promover e estimular a adoção de padrões de consumo mais sustentáveis. Com isso, foram formulados vários programas e leis, que normatizam e orientam os gestores públicos na adoção de novos referenciais de sustentabilidade em suas rotinas de trabalho. Dentre eles pode-se citar a A3P e o PLS.

O Plano de Gestão de Logística Sustentável (PLS) foi instituído em 05 de junho de 2012, através do decreto $n^{\circ} 7.746$, e regulamentado pela Instrução Normativa (IN) $n^{\circ}$ 10/2012 do Ministério do Planejamento, Orçamento e Gestão. Conforme o artigo $3^{\circ}$, dessa IN, os PLS são conceituados como:

[...] ferramentas de planejamento com objetivos e responsabilidades definidas, ações, metas, prazos de execução e mecanismos de monitoramento e avaliação, que permite ao órgão ou entidade estabelecer práticas de sustentabilidade e racionalização de gastos e processos na Administração Pública (BRASIL, 2012).

A IN no 10/2012 estabelece que todos os entes públicos deverão elaborar seus PLS e, posteriormente, devem publicá-los nos sites das respectivas organizações no prazo de 180 dias, contados a partir da referida publicação da IN.

Dessa forma, de acordo com Gazzoni et. al. (2016), a partir da criação do decreto que institui o PLS, todos os órgãos e entidades da Administração Pública Federal direta, autárquica, fundacional e as empresas estatais dependentes, são obrigados a se preocupar em promover práticas de sustentabilidade em suas rotinas de trabalho. Para elaboração do PLS, as instituições terão que se basear nas diretrizes da A3P, programa do governo federal que será discutido na próxima seção.

\subsection{AGENDA AMBIENTAL NA ADMINISTRAÇÃO PÚBLICA (A3P) E PRÁTICAS SUSTENTÁVEIS}

O Ministério do Meio Ambiente (MMA) criou o programa da A3P em 1999, devido à necessidade de inserir todos os entes públicos no contexto da gestão ambiental, atendendo assim ao princípio da eficiência e equilíbrio do meio ambiente, estabelecidos na Constituição brasileira de 1988 (MMA, 2017). O programa foi baseado nas diretrizes da Agenda 21 global, demostrando, segundo Araújo, Ludewigs e Carmo (2015), a sua ligação direta com os esforços globais na promoção de ações sustentáveis para produção e consumo. Apesar da A3P não ser de adesão obrigatória, o MMA recomenda a sua adoção pela administração pública 
direta e indireta, em suas três esferas: federal, estadual e municipal (LUIZ et al., 2013; FREITAS; BORGERT; PFITSCHER, 2011).

O objetivo da A3P é estimular os gestores públicos a adotarem, em suas atividades rotineiras, práticas de gestão socioambiental que levem à economia de recursos e redução de gastos, por meio do uso racional dos bens públicos, da gestão de resíduos, da licitação sustentável e da promoção da sensibilização, capacitação e qualidade de vida no ambiente de trabalho (MMA, 2009). Para esse objetivo ser alcançado é preciso a colaboração de todos os atores envolvidos na implantação da A3P, a fim de que ocorram mudanças de hábitos, visando à promoção da sustentabilidade na instituição.

Nesse sentido, a agenda foi pautada em 6 eixos temáticos, norteadores na adoção de práticas sustentáveis a serem adotadas pelos órgãos públicos (MMA, 2009):

O primeiro eixo refere-se ao uso racional dos recursos naturais e bens públicos e implica na redução do desperdício (MMA, 2016). De acordo com Prado (2015), esse eixo engloba o consumo eficiente de água, energia e madeira, a diminuição ou erradicação do uso de copos plásticos (que poderão ser substituídos por copos ou canecas de material nãodescartável), a utilização de lâmpadas econômicas (que devem ser apagadas quando os ambientes não estiverem em uso), a preferência pela utilização de papel reciclado (evitando o uso desnecessário, fazendo a impressão frente-e-verso e reutilizando-o como rascunho), o incentivo ao transporte coletivo e às caronas solidárias, entre outras práticas.

O segundo eixo trata da gestão adequada dos resíduos gerados, é regulamentado pela Política Nacional de Resíduos Sólidos - PNRS, Lei $\mathrm{N}^{\circ} 12.305 / 2010$ e pelo Decreto $\mathrm{N}^{\circ}$ 7.404/2010 que preveem a redução e a destinação ambientalmente adequada dos resíduos gerados pelas instituições públicas. A estruturação deste eixo engloba medidas que visam à implantação da coleta seletiva e da reciclagem, a reutilização dos resíduos sólidos e a destinação final ambientalmente adequada dos rejeitos (MMA, 2016). As ações desse eixo são pautadas na adoção da política dos 5R's: Repensar atitudes com o objetivo de diminuir a deterioração ambiental; Reduzir o consumo; Recusar produtos desnecessários ou que gerem impactos socioambientais significativos; Reutilizar; e Reciclar produtos (COGO; OLIVEIRA; TESSER, 2012).

O terceiro eixo fala da qualidade de vida no ambiente de trabalho, envolvendo os aspectos físicos, ambientais e psicológicos do local de trabalho. Sua principal finalidade é atender as necessidades do servidor, objetivando o aumento da sua produtividade e do seu bem estar (PRADO, 2015). Engloba assim, ações que buscam ampliação da participação dos 
servidores nos processos institucionais, redução do estresse, e garantia da acessibilidade, da segurança e da saúde no trabalho (MMA, 2016).

Já o quarto eixo, diz respeito à sensibilização e capacitação dos servidores. Seu principal objetivo é a mudança de hábitos, comportamentos e padrões de consumo. De acordo com Prado (2015), a sensibilização visa à promoção de campanhas com intuito de criar e/ou estimular uma consciência socioambiental nos gestores, servidores e outros atores envolvidos. Já a capacitação busca, através de minicursos, palestras e seminários, o desenvolvimento de competências socioambientais, institucionais e individuais (PRADO, 2015).

Enquanto que o quinto eixo temático refere-se às licitações sustentáveis. Seu principal propósito é a promoção da responsabilidade socioambiental nas aquisições de bens e nas contratações de serviços, obras e reformas, agregando critérios de sustentabilidade a esses procedimentos, a partir de uma visão sistêmica do processo produtivo (COGO; OLIVEIRA; TESSER, 2012). Para Prado (2015), este eixo encontra respaldo em distintos instrumentos normativos como leis, decretos, instruções e portarias. Podemos citar, como exemplo, a Instrução Normativa 01 de 2010, que regulamenta a utilização de critérios sustentáveis na aquisição de bens e na contratação de obras e serviços pelos órgãos do Poder Executivo (MMA, 2016).

Por fim, o sexto e último eixo aborda as construções sustentáveis. A estruturação desse eixo temático versa sobre construções sustentáveis, definidas como aquelas que consideram na sua concepção, constituição, operação e renovação, práticas reconhecidamente sustentáveis (MMA, 2016). Desta maneira, segundo Prado (2015), essas construções levam em consideração a redução dos resíduos gerados, a preservação ambiental, a qualidade do ambiente construído e a otimização do consumo de materiais, energia e água.

Para aderir formalmente à A3P é necessária a assinatura do Termo de Adesão, que é um instrumento que possui a finalidade de integrar esforços entre o MMA e o órgão público na implantação da agenda. As instituições podem ainda aderir à Rede A3P, que é um canal de comunicação que permite a troca de informações e experiências, entre os diversos órgãos públicos, em relação às temáticas da A3P (MMA, 2016).

A Agenda Ambiental na Administração Pública tem-se mostrado um importante instrumento norteador dos órgãos e entidades públicas sobre a promoção de ações sustentáveis. Nesse sentido, Carvalho e Sousa (2013) argumentam que através da A3P os gestores públicos fazem a programação de práticas sustentáveis, baseados nos eixos temáticos 
apresentados pelo programa, gerando economia, através do menor custo para a gestão pública e com o mínimo impacto ambiental possível.

Assim, esse trabalho se baseou nos eixos de sustentabilidade, preconizados pela A3P, para investigar as práticas sustentáveis adotadas na Universidade Federal Rural de Pernambuco/Unidade Acadêmica de Garanhuns - UFRPE/UAG.

\section{METODOLOGIA}

\subsection{ENQUADRAMENTO METODOLÓGICO}

Para alcançar os objetivos propostos, esse estudo possui caráter descritivo, ou seja, objetiva descrever as características de determinada população ou fenômeno ou ainda estabelecer a relação entre variáveis (GIL, 2011). Quanto à sua natureza, é classificado como qualitativo, pois procura interpretar certas variáveis que ajudarão no entendimento do comportamento humano (DIAS, 2010).

Já o método de pesquisa utilizado foi o estudo de caso, conceituado como uma abordagem empírica que visa analisar um fenômeno atual, dentro de seu contexto específico, no qual são utilizadas várias fontes de evidência (YIN, 2001).

Para coleta de dados foram utilizados dois instrumentos, um questionário e uma entrevista semiestruturada, os quais serão descritos na seção 3.3.

\subsection{ESCOLHA DA UNIDADE DE ANÁLISE}

A unidade de análise escolhida para este estudo de caso foi um dos campi da Universidade Federa Rural de Pernambuco, identificada aqui como Unidade Acadêmica de Garanhuns (UAG). A UFRPE/UAG foi o primeiro campus de extensão universitária do Programa de Expansão e Interiorização da Educação Superior criado no país, com o papel central de influir no desenvolvimento regional, tendo suas atividades iniciadas no segundo semestre de 2005 (UFRPE, 2017).

De acordo com o Plano de Desenvolvimento Institucional (PDI) da instituição, a UFRPE, em sua gestão, utiliza-se da responsabilidade socioambiental, considerando a sustentabilidade dos recursos naturais, econômicos e sociais em suas ações administrativas, além do que, vê como prioridade a efetivação de dois instrumentos de gestão ambiental: o PLS e a A3P. 
Dessa forma, justifica-se a escolha da UAG por esta ser uma instituição federal e por fazer parte da UFRPE, ou seja, também deve adotar uma gestão voltada para o desenvolvimento sustentável. Por conseguinte, como os técnicos administrativos pertencem à categoria que lida com maior frequência e mais diretamente com os processos de gestão do campus, optou-se por estudar como essa população específica da comunidade acadêmica adota práticas sustentáveis em suas rotinas e qual o seu grau de conhecimento a respeito de temáticas de sustentabilidade para a Administração Pública.

\subsection{INSTRUMENTOS E COLETA DE DADOS}

O levantamento de dados ocorreu através da aplicação de dois instrumentos: um questionário junto aos técnicos administrativos da UFRPE/UAG e uma entrevista semiestruturada realizada com o Diretor Administrativo do campus.

De acordo com Marconi e Lakatos (2008) e Gil (2011), o questionário é um instrumento para coleta de informações, constituído de uma série de perguntas, submetido a pessoas, com o objetivo de obter informações sobre conhecimentos, comportamentos, atitudes, interesses, valores e outros.

Assim, primeiramente, preparou-se um questionário contendo 12 questões, sendo: 11 fechadas (10 delas versaram sobre adoção de ações sustentáveis de acordo com os eixos da A3P e 01 procurava analisar o grau de conhecimento dos técnicos a respeito da A3P, da Agenda 21 e do PLS da UFRPE); e 01 questão aberta, na qual os respondentes deveriam elencar práticas consideradas sustentáveis, adotadas em seus setores, as quais não haviam sido enumeradas nas questões fechadas. Para construção dessas questões, utilizou-se como base: (1) a cartilha da A3P; (2) as ações sustentáveis listadas por Vogelmann Júnior (2014); e (3) as variáveis influentes sobre a qualidade de vida no trabalho, destacadas por Mandu et al. (2018).

Em seguida, o questionário foi sistematizado na ferramenta do Google Drive Formulários, e o link de acesso enviado por correio eletrônico (e-mail) a todos os técnicos administrativos do campus, (total de 87 servidores em 18/04/2018), com exceção da autora. O acesso a essa ferramenta foi liberado pelo período de uma semana (entre 18/04/2018 e 24/04/2018). A amostra da pesquisa foi constituída a partir do número de servidores que retornaram o questionário, totalizando assim, 64 servidores técnicos administrativos. As informações coletadas através desse instrumento foram organizadas com o auxílio de planilha eletrônica do software Excel® . 
Posteriormente, com o objetivo de averiguar quais as ações sustentáveis são incentivadas pela gestão, realizou-se uma entrevista semiestruturada com o técnico que ocupa a direção administrativa da UFRPE/UAG. A mesma foi gravada e, em seguida, transcrita para a análise das informações coletadas. De acordo com Martins e Theóphilo (2009), a entrevista semiestruturada é um instrumento de coleta de dados que tem a finalidade de compreender o significado que um entrevistado atribui a questões e situações, devendo ser conduzida através de um roteiro, no qual o pesquisador tem a liberdade de acrescentar novas questões. Nesse sentido, para a elaboração do roteiro dessa entrevista, utilizaram-se as disposições constantes na cartilha da A3P e no roteiro de ações sustentáveis organizado por Vogelmann Júnior (2014).

Por fim, todos os dados coletados foram organizados em 2 categorias: (1) Práticas adotadas na UFRPE/UAG em cada um dos eixos da A3P - Uso racional dos recursos naturais e bens públicos, Gerenciamento de resíduos sólidos, Qualidade de vida no ambiente de trabalho, Sensibilização e capacitação dos servidores, Contratações/Licitações Públicas Sustentáveis e Construções Sustentáveis; e (2) Grau de conhecimento dos técnicos a respeito de temáticas de sustentabilidade.

\section{ANÁLISE DOS RESULTADOS}

Essa seção apresenta os resultados obtidos através das respostas dos questionários aplicados junto aos técnicos administrativos e da entrevista semiestruturada efetivada com um dos gestores da UFRPE/UAG. Esses resultados buscam descrever as práticas adotadas por esses servidores e o grau de conhecimento destes a respeito de algumas temáticas de sustentabilidade voltadas para a gestão pública.

\subsection{PRÁTICAS ADOTADAS NA UFRPE/UAG DE ACORDO COM OS EIXOS DA A3P}

\subsubsection{Uso racional dos recursos naturais e bens públicos}

Com o objetivo de averiguar as práticas adotadas sobre o eixo Uso racional dos recursos naturais e bens públicos, uma das perguntas do questionário aplicado tratou da frequência com que os respondentes adotam algumas ações sustentáveis. As respostas estão descritas na Tabela 01 . 
Tabela 01 Frequência com que os técnicos administrativos adotam determinadas ações sustentáveis

\begin{tabular}{lccccc}
\hline \multicolumn{1}{c}{ Ação Sustentável } & Sempre & Frequentemente & Raramente & Nunca & $\begin{array}{c}\text { Não se } \\
\text { aplica }\end{array}$ \\
\hline $\begin{array}{l}\text { Apaga a luz ao término do expediente ou } \\
\text { quando se ausenta por período de tempo } \\
\text { prolongado }\end{array}$ & $79,7 \%$ & $20,3 \%$ & $0 \%$ & $0 \%$ & $0 \%$ \\
$\begin{array}{l}\text { Desliga o ar condicionado ou o ventilador ao } \\
\text { término do expediente ou quando se ausenta } \\
\text { por período de tempo prolongado }\end{array}$ & $78,1 \%$ & $21,9 \%$ & $0 \%$ & $0 \%$ & $0 \%$ \\
\hline $\begin{array}{l}\text { Fecha portas e janelas quando o ar } \\
\text { condicionado está ligado }\end{array}$ & $81,2 \%$ & $17,2 \%$ & $1,6 \%$ & $0 \%$ & $0 \%$ \\
\hline $\begin{array}{l}\text { Desliga os monitores do seu setor quando faz } \\
\text { uma pausa para descanso }\end{array}$ & $32,8 \%$ & $25 \%$ & $28,1 \%$ & $12,5 \%$ & $1,6 \%$ \\
\hline $\begin{array}{l}\text { Imprime ou faz cópia dos documentos em } \\
\text { frente-e-verso }\end{array}$ & $32,8 \%$ & $39,1 \%$ & $20,3 \%$ & $7,8 \%$ & $0 \%$ \\
\hline $\begin{array}{l}\text { Utiliza papel reciclado em substituição ao } \\
\text { papel branco }\end{array}$ & $60,9 \%$ & $37,5 \%$ & $1,6 \%$ & $0 \%$ & $0 \%$ \\
\hline $\begin{array}{l}\text { Reutiliza papéis para fazer bloco de } \\
\text { anotaçõs/rascunho }\end{array}$ & $59,4 \%$ & $28,1 \%$ & $12,5 \%$ & $0 \%$ & $0 \%$ \\
\hline $\begin{array}{l}\text { Substitui copos descartáveis por copos, canecas } \\
\text { ou xícaras de material durável }\end{array}$ & $53,1 \%$ & $20,3 \%$ & $17,2 \%$ & $6,3 \%$ & $3,1 \%$ \\
\hline
\end{tabular}

Fonte: elaborado pelos autores a partir dos dados da pesquisa

Pode-se observar que a grande maioria dos respondentes alegou adotar as práticas listadas na Tabela 01, sempre ou frequentemente. Fato que corrobora com a fala do diretor administrativo, quando observa que a adoção de práticas sustentáveis já está imbuída culturalmente na mentalidade dos servidores da UFRPE/UAG. Ele destacou que: "A gente observa o cuidado. São raros os setores, por exemplo, que deixam ao meio-dia, ficar arcondicionado ligado, lâmpada ligada. Então eu acho que culturalmente o servidor ele já tá consciente dessa matéria".

A ação adotada com menor frequência foi o desligamento de monitores quando se faz uma pausa para descanso, listada por $40,6 \%$ dos questionados como ação realizada raramente ou nunca. Nesse sentido, o diretor foi questionado se o Núcleo de Tecnologia da Informação (NTI) da Unidade programa os monitores para modo standy by (espera), após um determinado tempo sem uso. A esse questionamento o gestor afirmou não ter certeza absoluta, mas que acreditava que os servidores do NTI faziam esse trabalho. De acordo com Maurer e Lanes (2012), colocar o computador em modo standy by, quando não utilizado, é uma ação muito importante na economia de energia, mas para as autoras, o ideal seria desligar os monitores se o tempo de desuso for mais longo. Nessa direção, Prado (2005) estima que a combinação dos dois fatores (desligamento na hora do almoço e modo stand by no horário de funcionamento) pode diminuir até $35 \%$ do consumo de energia de um microcomputador. 
A utilização de papel reciclado e a substituição de copos descartáveis por outros de material durável são adotadas sempre ou frequentemente por $98,4 \%$ e $73,4 \%$ dos respondentes, respectivamente. Porém, isso ocorre porque esses hábitos são incentivados pela instituição. Já que, de acordo com o diretor, cerca de 90\% do papel adquirido pela instituição é reciclado e que só se utiliza papel branco para confecção de algum documento, no qual se exija que o material não seja reciclável. Além disso, afirmou que a UFRPE não compra mais copos descartáveis, o pouco que ainda se têm é o proveniente de estoque e, quando este estoque acabar, será adquirido uma quantidade mínima para suprir a necessidade de eventos ou de visitantes.

Além do que foi citado na Tabela 01, o diretor administrativo ainda destacou três ações que visam contribuir para a sustentabilidade do campus: todas as lâmpadas fluorescentes estão sendo paulatinamente substituídas por lâmpadas de Light Emitting Diode (LED), de menor consumo; os vigilantes são treinados para fazer uma ronda ao final do expediente e apagar as luzes de ambientes desocupados; e há ainda a revisão semestral de toda a instalação elétrica da Unidade. Essas atitudes são elencadas por Vogelmann Júnior (2014) como ações que visam à eficiência energética.

Outra questão abordou a forma de locomoção dos técnicos administrativos para o trabalho. Nesse sentido, observou-se que a 71,9\% dos respondentes se locomovem para UAG através de carro próprio, $12,5 \%$ vem para o trabalho a pé, 7,8\% utilizam ônibus, 1,6\% vem de carona (carro), e o restante $(6,2 \%)$ se utiliza de outros meios de transporte (táxi, moto e van). Analisou-se ainda que nenhum dos respondentes se locomove para o trabalho de bicicleta. Assim, observa-se que a utilização de transportes coletivos é pequena e que não há incentivo à carona solidária. Para Arasaki et al. (2016), a carona solidária é uma iniciativa que objetiva a melhoria do meio ambiente, da mobilidade urbana e da colaboração entre os indivíduos. Quando promovida pelas instituições, os benefícios são ainda maiores, impactando o desempenho, a produtividade, o clima organizacional e outros (ARASAKI et al., 2016).

Como destacado acima, a maioria dos técnicos se locomove para o trabalho com veículo próprio (71,9\%). Dessa forma, quando questionados sobre uma possível implantação da carona solidária através de incentivo da instituição, a maior parte deles (62\%) respondeu que ofereceria carona ou deixaria seu carro para pegar carona; $22 \%$ afirmaram que apenas ofereceriam carona; $10 \%$ não pegariam, nem ofereceriam carona; e 6\% não souberam responder. Diante disso, se houvesse o incentivo por parte da gestão à utilização de caronas solidárias, os servidores se mostraram propensos a realizar essa iniciativa. 
Em relação ao uso eficiente de água, foi relatado, na entrevista, que as torneiras tradicionais existentes nos banheiros do campus estão sendo paulatinamente substituídas por torneiras de fechamento automático.

Por fim, na questão aberta do questionário, em relação a esse eixo, um dos respondentes destacou a implantação do repositório virtual de monografias e TCCs, o que vai evitar o desperdício de papel, etiquetas e caixas utilizados na impressão, catalogação e arquivo da obra física.

\subsubsection{Gestão adequada dos resíduos gerados}

Esse eixo da A3P, de acordo com Gazzoni et al. (2018), abrange primeiramente uma gestão adequada de resíduos, no intuito de combater desperdícios, e posteriormente a utilização de formas de descarte corretas desses rejeitos. Nessa perspectiva, dois indivíduos da amostra dessa pesquisa alegaram fazer o descarte adequado de equipamentos eletrônicos e o descarte de material químico e biológico de forma orientada e responsável.

Quanto a isso, o diretor administrativo afirmou que o descarte de resíduos orgânicos (como, por exemplo, carcaça de animais e restos de experimentos orgânicos) é realizado pelos técnicos e terceirizados (que atuam em setores específicos), conforme a lei. Ainda, segundo o mesmo, a UFRPE/UAG tem contrato com uma empresa que realiza a coleta desse material, inicialmente armazenado em bombonas localizadas em pontos estratégicos do campus, para que, em seguida, seja levado à Recife, onde se faz a eliminação de acordo com a legislação específica.

O gestor assegurou ainda que o sistema de coleta seletiva está em fase de implantação na Unidade. Já existem lixeiras seletivas espalhadas por todo o campus, os servidores terceirizados, responsáveis pela limpeza, foram treinados e fazem a separação entre o lixo orgânico e o inorgânico. Porém, o diretor não soube informar se a prefeitura do município, responsável pela coleta de lixo, respeita a separação realizada pelos terceirizados, quando efetua a coleta.

Para implantação efetiva da coleta seletiva, o técnico que ocupa a direção administrativa da Unidade, destacou que a principal dificuldade tem sido realizar convênios com associações de catadores de lixo, pois muitas delas não são registradas e não estão devidamente constituídas, com isso não se pode firmar convênios como a legislação exige. Essa dificuldade também foi observada por Dias (2014), quando relatou, em seu estudo, que a primeira barreira para implantação do projeto "Recicla UFBA" foi encontrar uma cooperativa 
de reciclagem que atendesse aos requisitos do Decreto Presidencial $n^{0}$ 5.940/2006, principalmente no que diz respeito à documentação exigida e à infraestrutura necessária.

\subsubsection{Qualidade de vida no ambiente de trabalho (QVT)}

Com o intuito de analisar as ações referentes a esse eixo, o questionário abordou algumas questões que buscavam investigar a percepção dos técnicos a respeito de variáveis que influenciam a QVT, destacadas por Mandu et al. (2017) e pela cartilha A3P. Os dados coletados a esse respeito estão descritos na Tabela 02 .

Tabela 02 Resumo das variáveis que influem a QVT na UFRPE/UAG

\begin{tabular}{lccccc}
\hline \multicolumn{1}{c}{ Variáveis } & Sempre & Frequentemente & Raramente & Nunca & $\begin{array}{c}\text { Não } \\
\text { sabe }\end{array}$ \\
\hline Aproveitamento de habilidades & $12,5 \%$ & $65,6 \%$ & $15,6 \%$ & $4,7 \%$ & $1,6 \%$ \\
Autonomia nas atividades & $15,6 \%$ & $76,6 \%$ & $4,7 \%$ & $0 \%$ & $3,1 \%$ \\
Existência de preconceitos & $1,6 \%$ & $9,4 \%$ & $45,3 \%$ & $37,5 \%$ & $6,2 \%$ \\
Promoção de atividades de integração social & $4,7 \%$ & $4,7 \%$ & $7,80 \%$ & $65,6 \%$ & $17,2 \%$ \\
e qualidade de vida & $29,7 \%$ & $42,2 \%$ & $20,3 \%$ & $3,1 \%$ & $4,7 \%$ \\
Privacidade Pessoal & $29,7 \%$ & $53,1 \%$ & $10,9 \%$ & $1,6 \%$ & $4,7 \%$ \\
Liberdade de expressão & $21,9 \%$ & $53,1 \%$ & $9,4 \%$ & $10,9 \%$ & $4,7 \%$ \\
Tratamento imparcial & $0 \%$ & $20,3 \%$ & $45,3 \%$ & $28,1 \%$ & $6,3 \%$ \\
Realização de horas extras & Variáveis & Parcialmente & $\mathbf{N a ̃ o}$ & Não sabe \\
\hline & $45,30 \%$ & $31,30 \%$ & $21,90 \%$ & $1,60 \%$ \\
\hline Salubridade do ambiente de trabalho & $21,90 \%$ & $51,6 \%$ & $26,60 \%$ & $0 \%$ \\
\hline Ergonomia: Equipamentos e mobiliário & & & &
\end{tabular}

Fonte: elaborado pelos autores a partir dos dados da pesquisa

A partir da análise dos resultados da Tabela 02, pode-se observar que as variáveis de aproveitamento de habilidades, autonomia nas atividades, privacidade pessoal, liberdade de expressão, tratamento imparcial são percebidas sempre ou frequentemente por mais de $70 \%$ dos servidores. De acordo com o MMA (2009), essas variáveis influem positivamente na qualidade de vida no ambiente de trabalho. Outra variável que implica a satisfação com o ambiente laboral, conforme MMA (2009), é o controle adequado da jornada de trabalho. Nesse sentido, a maioria dos entrevistados $(73,4 \%)$ respondeu que nunca ou raramente é necessário realizar horas extras para o bom andamento das atividades, fato que confirma que há um controle adequado da jornada.

Observou-se ainda que $11 \%$ dos respondentes alegaram perceber algum tipo de preconceito em seu ambiente de trabalho. Apesar de ser um quantitativo pequeno, esse 
número é alto, se comparado ao que a $\mathrm{A} 3 \mathrm{P}$ recomenda. Já que a Agenda preconiza que para se ter qualidade de vida no ambiente de trabalho, este deve ser livre de preconceito.

Em relação à promoção de práticas de integração social e qualidade de vida (ginástica laboral, oficinas de talento, dinâmicas de grupo e outros), 17,2\% dos respondentes não sabem se são promovidas e 73,4\% afirmaram que essas ações nunca ou raramente acontecem. Nesse sentido, Hipólito et al. (2017) constataram que o incentivo à atividade física, à realização de exercícios para melhora da postura corporal, à ginástica laboral e à promoção de programas que visem redução de peso, melhoram a saúde, a autoestima e a produtividade, gerando benefícios para o trabalhador e para a instituição. No que diz respeito à salubridade do ambiente de trabalho, 21,9\% dos entrevistados consideram o ambiente insalubre, enquanto 45,3\% avaliam o ambiente laboral como saudável.

A entrevista com a direção administrativa revelou que a Unidade possui carência em relação a programas e campanhas que promovam a melhoria da qualidade de vida dos servidores. De acordo com o gestor, é necessário, em primeiro lugar, fazer uma reestruturação completa do setor médico da UFRPE/UAG, para que este disponha de profissionais especialistas em saúde ocupacional. O diretor ainda destacou que o campus não possui mobiliário específico para pessoas com problemas de obesidade. Nessa perspectiva, 51,6\% dos técnicos administrativos responderam que a ergonomia dos móveis e equipamentos é parcialmente adequada às suas necessidades, enquanto que $26,6 \%$ consideram a ergonomia totalmente inadequada. Resultado semelhante foi observado por Mandu et al. (2017), quando analisou a percepção dos técnicos administrativos sobre o mobiliário do campus de Serra Talhada da UFRPE, 32,7\% consideram a ergonomia do móveis inadequada, enquanto 45,4\% avaliam essa ergonomia como parcialmente apropriada.

\subsubsection{Sensibilização e capacitação dos servidores}

Para Dias (2014), a conscientização socioambiental dos indivíduos é primordial na promoção de qualquer ação sustentável, sendo necessário para tanto, dispensar atenção especial ao eixo da A3P que trata de sensibilização e capacitação dos servidores. O autor ainda destaca que as principais ações desse eixo são cursos, campanhas, palestras e publicações que versem sobre as temáticas de sustentabilidade na administração pública. Assim, observou-se que as iniciativas em relação à sensibilização e capacitação dos servidores da UFRPE/UAG, sobre práticas sustentáveis, são ainda muito incipientes. Quando questionados se já haviam realizado algum curso sobre a temática de sustentabilidade no 
serviço público, promovido pela instituição, a grande maioria dos técnicos (75\%) respondeu que nunca havia feito nenhum curso.

Por outro lado, 16 indivíduos (25\% do total) responderam que já participaram de cursos promovidos pela UFRPE/UAG. Porém esses servidores indicaram apenas 2 iniciativas nesse sentido, o curso intitulado "Responsabilidade socioambiental", realizado em maio de 2017, que versou sobre as práticas da A3P e o "I STAES - I Seminário de Técnicos Administrativos de Educação Superior", realizado em outubro de 2017, que abordou algumas temáticas sobre sustentabilidade no serviço público.

Os técnicos foram questionados ainda, se observavam campanhas de sensibilização, destinadas a servidores, sobre a diminuição do desperdício ou sobre a adoção de práticas sustentáveis em seu ambiente de trabalho. A partir das respostas a esse questionamento, podemos notar que as ações de sensibilização para a adoção de atitudes sustentáveis, promovidas pela UFRPE/UAG, são realizadas ocasionalmente, já que $88 \%$ dos servidores alegaram que esse tipo de prática é percebida, às vezes, ou, simplesmente, não é observada na instituição. Resultados semelhantes foram obtidos por Luiz et al. (2013), quando analisou as ações de sensibilização promovidas por um Instituto Federal de Educação, chegando à conclusão de que a organização abordava esse tipo de prática de maneira incipiente, além disso, não possuía projetos de produção e divulgação de material educativo voltado à preservação e conservação ambiental.

Diante disso, observa-se que há a necessidade de maior incentivo de ações de sensibilização e capacitação sobre práticas socioambientais na UFRPE/UAG. Isso porque, segundo Gazzoni et al. (2018), essas ações são de extrema importância para ampliação do conhecimento dos servidores no que se refere aos tópicos de desenvolvimento sustentável.

\subsubsection{Licitações Sustentáveis}

As práticas sustentáveis sobre licitações públicas adotadas pela UFRPE/UAG, apontadas pelo diretor administrativo do campus, foram: (1) $90 \%$ do papel comprado é de material reciclado; (2) sempre é realizada a compra de eletrodomésticos e eletroeletrônicos com selo PROCEL, que, de acordo com a Eletrobras (2013), identifica os produtos com o melhor índice de eficiência energética em uma dada categoria de equipamentos; e (3) o mobiliário do campus é fabricado em MDF ou MDP. Todas essas práticas são listadas por Vogelmann Júnior (2014) como ações que promovem o desenvolvimento sustentável nas 
instituições públicas. Ainda em relação a esse eixo, um dos respondentes destacou que, sempre que possível a instituição dá preferência à compra de materiais sustentáveis.

\subsubsection{Construções Sustentáveis}

No que diz respeito às construções sustentáveis, o gestor ressaltou algumas práticas observadas na UFRPE/UAG. Segundo ele, a maioria das entradas, portas, banheiros e estacionamentos são adaptados para o livre acesso de pessoas portadoras de deficiência ou com mobilidade reduzida. Já nas áreas internas do prédio administrativo e de um dos prédios de professores, são utilizadas divisórias ao invés de paredes, o que, segundo Vogelmann Júnior (2014), é uma ação sustentável, pois dá maior flexibilidade à edificação em relação a mudanças de uso do imóvel. O diretor destacou ainda que, no projeto de novos prédios, já há a exigência que estes possuam sistema de captação de água pluvial e placas de energia solar.

\subsection{GRAU DE CONHECIMENTO DOS TÉCNICOS A RESPEITO DE TEMÁTICAS DE SUSTENTABILIDADE}

Os resultados relativos ao grau de conhecimento dos técnicos administrativos da UFRPE/UAG em relação às temáticas de sustentabilidade voltadas à Administração Pública estão descritos na Tabela 3.

Tabela 03 Grau de conhecimento dos técnicos da UFRPE/UAG a respeito de temáticas sustentáveis

\begin{tabular}{cccccc}
\hline \multirow{2}{*}{$\begin{array}{c}\text { Temáticas } \\
\text { sustentáveis }\end{array}$} & $\begin{array}{c}\text { Nenhum } \\
\text { conhecimento }\end{array}$ & $\begin{array}{c}\text { Pouco } \\
\text { conhecimento }\end{array}$ & $\begin{array}{c}\text { Razoável } \\
\text { conhecimento }\end{array}$ & $\begin{array}{c}\text { Bom } \\
\text { conhecimento }\end{array}$ & $\begin{array}{c}\text { Grande } \\
\text { conhecimento }\end{array}$ \\
\hline PLS da UFRPE & $40,6 \%$ & $31,3 \%$ & $17,2 \%$ & $10,9 \%$ & $0,0 \%$ \\
A3P & $42,2 \%$ & $32,8 \%$ & $17,2 \%$ & $7,8 \%$ & $0,0 \%$ \\
Agenda 21 & $45,3 \%$ & $29,7 \%$ & $18,7 \%$ & $4,7 \%$ & $1,6 \%$ \\
\hline
\end{tabular}

Fonte: elaborado pelos autores a partir dos dados da pesquisa.

O Plano de Gestão de Logística Sustentável (PLS) da UFRPE, apesar de ter sido publicado recentemente (em janeiro de 2018), é o instrumento mais conhecido dentre os listados na Tabela 3 , pois $28,1 \%$ dos entrevistados asseguraram ter razoável ou bom conhecimento sobre ele. Em contrapartida, a Agenda 21 foi apontada como o programa menos conhecido, já que 45,3\% dos respondentes não possuem conhecimento algum a seu respeito.

Em resumo, nota-se que o conhecimento dos servidores a respeito das temáticas sustentáveis em análise é muito pequeno. Visto que mais de $70 \%$ dos técnicos administrativos da UFRPE/UAG possuem pouco ou nenhum entendimento sobre a A3P, a Agenda 21 e o PLS 
da UFRPE, instrumentos essenciais, que orientam os servidores e gestores públicos na implementação de práticas sustentáveis em seus ambientes de trabalho. Assim, se há baixo entendimento dos atores envolvidos a respeito dessas ferramentas norteadoras, haverá dificuldades de implantação do desenvolvimento sustentável na UFRPE/UAG. Diante disso, faz-se necessária a criação de mecanismos que possibilitem maior disseminação desses instrumentos.

Nesse sentido, Gazzoni et al. (2018), ao estudar o grau de conhecimento sobre temáticas sustentáveis de toda a comunidade acadêmica de uma IES, encontrou resultados semelhantes a esta pesquisa. Ele observou que havia ampla deficiência no entendimento de servidores a respeito de tópicos de sustentabilidade (logística reversa, PLS, A3P, Agenda 21 e outros) e destacou a necessidade de maior engajamento dos atores envolvidos, sendo imprescindível a implantação de uma política institucional voltada para o desenvolvimento sustentável.

\section{CONSIDERAÇÕES FINAIS}

A implantação da cultura de sustentabilidade na Administração Pública não tem sido uma tarefa fácil, pois, para que isso ocorra, é necessário transformação, modificação de hábitos e mudança da forma de pensar a Gestão Pública.

A partir dos resultados dessa pesquisa, pode-se notar que na UFRPE/UAG já existem várias inciativas pontuais e individuais de ações sustentáveis no ambiente de trabalho. Porém, não se percebeu nenhuma política institucional que vise o desenvolvimento sustentável dentro da organização, apesar da instituição já possuir alguns documentos de planejamento que versem sobre essa temática (PDI e PLS). Além disso, observou-se que, no geral, os técnicos administrativos possuem conhecimento limitado a respeito de instrumentos essenciais que norteiam a administração pública na implantação de práticas de sustentabilidade, fato que pode acarretar dificuldades no estabelecimento de ações nesse sentido. Com isso, sugere-se a criação de mecanismos de sensibilização e capacitação sobre o referido tema, tendo em vista que os dados obtidos nessa pesquisa mostraram que a realização de cursos e campanhas sobre a temática não são frequentes no campus estudado.

Dessa forma, espera-se que esse estudo tenha contribuído para o esclarecimento das ações socioambientais praticadas na UFRPE/UAG, além de ter despertado o interesse dos envolvidos, podendo servir de base para a instauração de uma gestão pública mais eficiente. 
No que concerne às limitações dessa pesquisa, observou-se que para um melhor entendimento das práticas adotadas, seria necessária a realização de entrevistas com chefes de setores específicos, como compras, engenharia e almoxarifado. Outra limitação encontrada foi o fato de a análise ter sido restringida à categoria de técnicos administrativos. Deste modo, sugere-se que estudos futuros possam analisar as práticas sustentáveis adotadas em outras universidades, considerando toda a comunidade acadêmica (técnicos, professores e alunos), com enfoque em um dos seis eixos preconizados pela A3P.

\section{REFERÊNCIAS}

ARASAKI, Paula Kaneoya et al. Contribuições da carona solidária no processo de compartilhamento do conhecimento. Revista de Gestão e tecnologia. Florianópolis, SC. v. 6, n. 3 , p. $40-55,2016$.

ARAÚJO, Carolina Lopes; LUDEWIGS, Thomas; CARMO, Eliane Almeida do. A Agenda Ambiental na Administração Pública desafios operacionais e estratégicos. Desenvolvimento em Questão, Ijuí, v. 13, n. 32, p. 21-47, 2015.

BARBIERI, José Carlos et al. Inovação e Sustentabilidade: novos modelos e proposições. RAE - Revista de Administração de Empresas, São Paulo, v. 50, n. 2, p. 146-154,. 2010.

BERNARDES, Leandro dos Santos et al. Sustentabilidade e inovação social: o lixo que gera oportunidades. Revista Gestão e Sustentabilidade Ambiental, Florianópolis, v. 5, n. 2, p. 785-813, 2017.

BOFF, Leonardo. Sustentabilidade: o que é - o que não é. Petrópolis, Rio de Janeiro, 2017

BRASIL. Constituição (1988). Constituição da República Federativa do Brasil. Brasília. Secretária de Logística e Tecnologia da Informação do Ministério do Planejamento, Orçamento e Gestão, Instrução Normativa No 10, de 12 de novembro de 2012.

BRUNDTLAND, Gro Harlem et al. Nosso Futuro Comum. 2 ed. Rio de Janeiro: Fundação Getúlio Vargas, 1991.

CARVALHO, Denis Barros de; SOUSA, Evangelina da Silva. Agenda Ambiental da Administração Pública (A3P) e licitações sustentáveis: um estudo no restaurante universitário da Universidade Federal do Piauí. In: COLÓQUIO INTERNACIONAL SOBRE GESTÃO UNIVERSITÁRIA NAS AMÉRICAS, 8., 2013, Buenos Aires. Anais... . Florianópolis: Inpeau (instituto de Pesquisas e Estudos em Administração Universitária), 2013. p. 1 - 16.

COGO, Giselle Alves da Rocha; OLIVEIRA, Ivanir Luiz de; TESSER, Daniel Poletto. Agenda Ambiental na Administração Pública (A3P) - um instrumento a favor da sustentabilidade na Administração Pública. In: ENCONTRO NACIONAL DE 
ENGENHARIA DE PRODUCAO, 32., 2012, Bento Gonçalves. Anais... . Bento Gonçalves: ABEPRO, 2012. p. 1 - 10.

DIAS, Marlise There. Construção do conhecimento e metodologia da pesquisa. Natal: [s.n.], 2010. 256p.

DIAS, Andréia Lé. Gestão ambiental na UFBA sob a perspectiva dos eixos temáticos da A3P. 2014. 212 f. Dissertação (Mestrado) - Curso de Pós-graduação em Estudos Interdisciplinares sobre a Universidade, Universidade Federal da Bahia, Salvador, 2014.

ELETROBRAS. Regulamento para concessão do selo PROCEL de economia de energia (revisão - IV). 2013.

FERREIRA, Ana Paula Alf Lima et al. A prática de sustentabilidade: um estudo bibliométrico com relação à percepção dos pesquisadores da área de administração. Revista metropolitana de sustentabilidade, São Paulo, v. 5, n. 3, p. 44-60, 2015.

FREITAS, Claudio Luiz de; BORGERT, Altair; PFITSCHER, Elisete Dahmer. Agenda Ambiental na Administração Pública: uma análise da aderência de uma IFES as diretrizes propostas pela A3P. In: COLÓQUIO INTERNACIONAL SOBRE GESTÃO UNIVERSITÁRIA NA AMÉRICA DO SUL, 11., 2011, Florianópolis. Anais... . Florianópolis: UFSC, 2011. p. 1 - 16.

GAZZONI, Fernando et al. A influência de fatores individuais no conhecimento sobre o Plano de Gestão de Logística Sustentável. Revista de Gestão do Unilasalle, Canoas, v. 5, n. 2, 2016.

GAZZONI, Fernando et al. O papel das IES no desenvolvimento sustentável: estudo de caso da Universidade Federal de Santa Maria. Revista GUAL, Florianópolis, v. 11, n. 1, p. 48-70, 2018.

GIL, Antônio Carlos. Métodos e Técnicas de Pesquisa Social. 6 ed. São Paulo: Atlas S.A., 2011. $200 \mathrm{p}$.

HIPÓLITO, Maiza Claudia Vilela et al . Qualidade de vida no trabalho: avaliação de estudos de intervenção. Revista Brasileira Enfermagem, Brasília, v. 70, n. 1, p. 189-197, 2017.

LIMA, André dos; SLOMSKI, Vilma Geni; ROCHA, Luis Fernando da. da et al. Sustentabilidade empresarial: concepções e ações ambientais de gestores do setor alimentício. Revista razão contábil e finanças, Fortaleza, v. 4, n. 2, p. 139-156, 2013.

LUIZ, Lilian Campagnin et al. Agenda Ambiental na Administração Pública (A3P) e Práticas de Sustentabilidade: Estudo Aplicado em um Instituto Federal de Educação, Ciência e Tecnologia. Administração pública e gestão social, v. 5, n. 2, p. 54-62, 2013.

LUIZ, Lilian Campagnin; PFITSCHER, Elisete Dahmer; ROSA, Fabrícia Silva da. Plano de Gestão de Logística Sustentável: proposição de ações e indicadores socioambientais para avaliar o desempenho nos órgãos públicos federais. Revista de Administração da UFSM, Santa Maria, v. 8, Ed. Especial XVI ENGEMA, p. 08-27, 2015. 
MACIEL, Dayane dos Santos Costa; FREITAS, Luciana Santana de. Utilização do método FMEA na identificação e análise dos impactos ambientais causados pelos postos de combustíveis: um estudo de caso. Revista de Administração da UFSM, Santa Maria, v. 7, número 4, p. 570-589, 2014.

MACULAN, Calusa Grendene et al. Implantação da sustentabilidade: a perspectiva dos próreitores de uma IFES do interior do estado do Rio Grande do Sul, Brasil. In: FÓRUM INTERNACIONAL ECOINOVAR, 5., 2016, Santa Maria. Anais... . Santa Maria: ECOINOVAR, 2016. p. 1 - 15.

MANDU, Maria Jaqueline da Silva et al. Aplicação de diretrizes da agenda ambiental na Administração Pública: estudo de caso na Universidade Federal Rural de PernambucoUnidade Acadêmica de Serra Talhada. In: EDITORA POISSON (Org.). Sustentabilidade e Responsabilidade Social em foco. Vol.2. Belo Horizonte: Poisson, 2018.

MARCONI, Marina de Andrade; LAKATOS, Eva Maria. Fundamentos de metodologia científica. 6. ed. São Paulo: Atlas, 2008.

MARTINS, Gilberto Andrade; THEÓPHILO, Carlos Renato. Metodologia da investigação científica para ciências sociais aplicadas. 2. ed. São Paulo: Atlas, 2009

MAURER, Eduarda Bruna; LANES, Letícia B. F. Práticas sustentáveis em TI. Unoesc \& Ciência - ACET, Joaçaba, SC, v. 3, n. 2, p. 187-194, 2012.

MELLO, Leonardo Freire de; OJIMA, Ricardo. Além das certezas e incertezas: desafios teóricos para o mito da explosão populacional. In: ENCONTRO NACIONAL DE ESTUDOS POPULACIONAIS, 14., 2004, Caxambu. Anais ... . Caxambu: ABEP, 2004. p. 1 - 23.

MMA. Ministério do Meio Ambiente. A3P-Agenda Ambiental na Administração Pública. 5. ed. Brasília, 2009. 100 p.

. Cartilha A3P - Como Implantar a A3P. 2. ed. Brasília, 2016. 20 p.

$39 \mathrm{p}$.

Gestão socioambiental nas universidades públicas: A3P. Brasília, 2017.

ONU. Organização das Nações Unidas. Agenda 21: Nações Unidas, 1992. Disponível em: < http://www.mma.gov.br/responsabilidade-socioambiental/agenda-21/agenda-21-global > . Acesso em: 12 abr. 2018.

PEDROSO, Marcelo Caldeira. Casos Sustentáveis. Gv-executivo, [S.L.], v. 6, n. 2, p. 25-29, mar./abr. 2007. Disponível em: $<$ http://rae.fgv.br/gv-executivo/vol6-num2-2007/casossustentaveis $>$. Acesso em: 21 abr. 2018.

PEGORIN, Maria Cristina; SANTOS, Darliene Costa dos; MARTINS, Ivan de Souza Costa. A aplicação da Agenda Ambiental no Setor Público: estudo de caso em uma Instituição da Administração Pública Federal Direta. In: CONGRESSO NACIONAL DE EXCELÊNCIA 
EM GESTÃO, 10., 2014, Rio de Janeiro. Anais... . Rio de Janeiro: INOVARSE, 2014. p. 1 14.

PEREIRA, Andréia de Souza. Educação superior e sustentabilidade: um estudo sobre a percepção dos atores do campus Alto Paraopeba / UFSJ / MG. 2013. 154 f. Dissertação (Mestrado) - Curso de Pós Graduação em Administração Pública, Universidade Federal de Lavras, Lavras, 2013.

PRADO, Walkiria Cavalcanti. Gestão Participativa A3P (Agenda Ambiental na Administração Pública) na Prefeitura da cidade do Recife: Contribuições da Educação a Distância. 2015. 153 f. Dissertação (Mestrado em Tecnologia e Gestão em EAD) Universidade Federal Rural de Pernambuco, Unidade Acadêmica de Educação a Distância e Tecnologia, Recife, 2015.

PRADO, André Alves. Economia do consumo de energia em microcomputadores. Janus, v. 2, n. 2, p. 111-121, 2005.

RODRIGUES, Carolina. Empreendedorismo e Sustentabilidade Social na Terceira Idade. In: CONFERêNCIA IBÉRICA DE EMPREENDEDORISMO, 5., 2015, Oeiras. 5a Conferência Ibérica de Empreendedorismo. Oeiras: Empreend - Associação portuguesa para o empreendedorismo, 2015. p. 67 - 72.

RUFINO, Bruno Hadley Vasconcelos; ANDRADE, José Ibernon Campos de. Agenda Ambiental na Administração Pública (A3P): Importância e Aplicação para os municípios que compreendem a Área de Proteção Ambiental da Serra de Baturité. Redenção, 2014.

SOARES, Kamyle Braga et al. Critérios de sustentabilidade ambiental na Administração Pública Federal: vantagens e desvantagens com base na Instrução Normativa 01/2010. Conexões, Ciência e Tecnologia, v. 11, n. 3, p. 50-63, 2017.

UFRPE. Universidade Federal Rural de Pernambuco. Plano de Desenvolvimento Institucional (PDI) UFRPE 2013-2020 - Revisado. Recife, 2017. 203 p.

VELTER, Aline Nadalin et al. O estudo da Sustentabilidade na Administração: um levantamento dos "hot topics" publicados na última década. In: SEMINÁRIOS DE ADMINISTRAÇÃO, 13., 2010, São Paulo. Anais... . São Paulo: SemeAd, 2010. p. 1 - 16.

VOGELMANN JUNIOR, Jorge Carlos. Roteiro Prático de Ações Sustentáveis na Administração Pública. Porto Alegre: ESAF, 2014. 25 p.

YIN, Robert K. Estudo de caso: planejamento e métodos. 2. Ed. Porto Alegre: Bookman, 2001. 